\title{
MODEL PEMBELAJARAN KETERAMPILAN TENDANGAN PENCAK SILAT (AKIS) UNTUK ANAK SMA
}

\author{
Akis Mayanto \\ Universitas Muhadi Setiabudi Brebes, Jawa Timur \\ email: akisfik@gmail.com
}

\begin{abstract}
ABSTRAK
Tujuan dari penelitian dan pengembangan ini adalah untuk menghasilkan model pembelajaran pencak silat untuk usia SMA. Penelitian ini menggunakan metode penelitian pengembangan Research \& Development (R \& D) dari Borg and Gall antara lain: (1) analisis kebutuhan, (2) evaluasi ahli (evaluasi produk awal); (3) ujioba terbatas (ujicoba kelompok kecil); (4) ujicoba utama (field testing), (5) Uji efektifitas model. Dari tes awal yang dilakukan diperoleh rata-rata keterampilan tendangan pencak silat siswa sebesar 42,23, kemudian setelah diberikan perlakuan berupa model keterampilan tendangan pencak silat diperoleh rata-rata kemampuan keterampilan pencak silat siswa sebesar 85,80. Berdasarkan hasil pengembangan dapat disimpulkan bahwa dengan model pembelajaran keterampilan tendangan pencak silat untuk siswa SMA dapat dikembangkan dan diterapkan dalam pembelajaran pendidikan jasmani di sekolah.
\end{abstract}

Kata Kunci: pengembagan, model, pencak silat

\section{ABSTRACT}

The purpose of this research and development is to produce pencak silat learning models for high school age. This study uses Research \& Development $(R \& D)$ development research methods from Borg and Gall, among others: (1) needs analysis, (2) expert evaluation (initial product evaluation); (3) limited testing (small group trials); (4) main testing (field testing), (5) Test the effectiveness of the model. From the preliminary tests conducted, it was found that the average students' pencak silat kick skills were 42.23, then after being given treatment in the form of a pencak silat kick skills model, the average skills of pencak silat students were obtained at 85.80. Based on the results of the development it can be concluded that the learning model of pencak silat kick skills for high school students can be developed and applied in physical education learning in schools.

Keywords: development, model, pencak silat

\section{PENDAHULUAN}

Sistem pendidikan nasional di dalamnya terdapat muatan kurikulum yang terdiri dari berbagai kompetensi dan materi yang sengaja dirancang untuk membelajarkan siswa (Kemenagpora 2011). Salah satu muatan yang terintegrasi dalam kurikulum adalah pendidikan jasmani, olahraga dan kesehatan. pendidikan jasmani adalah suatu proses pembelajaran melalui aktivitas jasmani yang didesain untuk meningkatkan kebugaran jasmani, mengembangkan keterampilan motorik, pengetahuan dan perilaku hidup sehat dan aktif, sikap sportif, dan kecerdasan emosi (Winarno 2011; Tangkudung 2013; Tite 2013).

Sebagai seorang pendidik, guru penidikan jasmani harus mampu mengoptimalkan seluruh aspek diri siswa agar tujuan pembelajaran tercapai (Zain 
and Aswan 2006). Proses pembelajaran yang menarik, penggunaan metode, sarana, serta pemanfaatan berbagai sumber belajar yang bervariasi akan membantu siswa untuk mencapai tujuan pembelajaran lebih maksimal. Proses pendidikan, sejatinya bermuara pada tercapainya tujuan pendidikan nasional. Sedangkan tujuan tersebut akan dicapai melalui proses pembelajaran dengan tujuan yang lebih spesifik (Hariyanto 2013). Agar tujuan pembelajaran tercapai dengan baik, maka guru harus memiliki melaksanakan pembelajaran dengan menarik untuk meningkatkan aktivitas siswa (Nara and Hartini 2010). Dengan berbagai variasi model pembelajaran, maka siswa akan lebih tertarik melakukan lebih sering tanpa bosan dengan frekuensi melakukan yang tinggi. Oleh sebab itu maka penting bagi guru untuk memiliki perbendaharaan variasi model pembelajaran yang tepat dan beragam.

Dalam sajian kurikulum pendidikan jasmani olahraga dan kesehatan, salahsatu materi yang disakjikan di Sekolah Menengah Atas yang belum banyak dikembangkan variasi model pembelajarannya adalah Pencak silat (Naharsari 2008). Pencak silat merupakan bagian dari budaya bangsa, sehingga terintegrasi dalam kurikulum. Pencak silat memiki karakteristik keterampilan bela diri baik dalam pertahanan maupun menyerang (Hariyadi 2009; Naharsari 2008; Lesmana 2012). Seringkali pembelajaran pencak silat di sekolah terutama SMA, disamakan dengan proses latihan. Padahal dalam pembelajaran perlu dipertimbangkan aspek fleksiilitas sarana, tutntutan keterampilan yang tidak terlalu tingi, kemampuan kognitif serta kemenarikan pembelajaran (Genel 1980; Musfiqon 2012; Sihkabuden 2005).

Berdasarkan hasil observasi yang dilakukan peneliti pada bulan November 2016 di sebuah SMA di Jakarta Timur, diperoleh hasil bahwa, dalam pembelajaran pencak silat, guru masih menggunakan metode konvensional dengan gaya komando dan penugasan. Siswa melakukan pemanasan, kemudian guru memberi contoh dan siswa melakukan. Meskipun demikian guru sudah menggunakan penugasan secara berkelompok, sehingga dapat mengurangi sedikit kebosanan, namun dalam proses observasi, peneliti menemukan bahwa mayoritas siswa merasa bosan pada paruh jam pelajaran karena terkesan monoton, gerakan yang dilakukan adalah gerakan yang sama yang diulang-ulang, hal tersebut 
sebenarnya telah dirasakan juga oleh guru berdasarkan hasil wawancara peneliti dengan guru, guru menyatakan memang siswa pada pembelajaran pencak silat seringkali merasa bosan dipertengahan jam pelajaran. Guru menyatakan bahwa hal tersebut memang dikarenakan masih minim variasi model pembelajaran pencak silat yang dimiliki.

Berdasarkan hasil wawancara dengan guru, guru menyatakan perlu adanya inovasi variasi model pembelajaran pencak silat yang lebih banyak agar dalam sebuah pembelajaran bisa memilih berbagai variasi tersebut. Siswa juga telah ditanya oleh peneliti terkait perlunya variasi pembelajaran pencak silat, dan 97\% menyatakan setuju jika ada pengembangan variasi model pembelajaran pencak silat yang lebih menarik. Dengan demikian maka perlu adanya inovasi pengembangan pembelajaran pencak silat untuk membantu guru meningkatkan efektifitas dan kemenarikan pembelajarannya, serta membantu siswa belajar lebih baik tentang pencak silat sehingga mampu memperoleh prestasi belajar yang lebih baik.

Tujuan akhir dari penelitian pengembangan ini adalah menghasilkan produk berupa buku yang berisikan model pembelajaran keterampilan tendangan pencak silat untuk SMA, sehingga dapat melengkapi bantuan belajar yang ada pada saat ini, yakni agar pembelajaran siswa dapat lebih: 1) Efektif, artinya merupakan kelengkapan dalam meningkatkan efektivitas atau kemudahan siswa dalam mengembangkan kemampuan teknik daasr pencak silat. 2) Efisiensi, maksudnya merupakan kelengkapan bantuan belajar, dimana dengan biaya dan waktu yang minimal sehingga dapat diperoleh hasil yang maksimal dalam materi pencaksilat atas. 3) Menarik, artinya merupakan kelengkapan belajar yang memiliki daya tarik sehingga siswa dapat termotivasi untuk memanfaatkannya dan dapat belajar lebih maksimal lagi.

Model dapat sebagai dikatakan sesuatu yang menggambarkan pola berfikir. Sebuah model menggambarkan keseluruhan konsep yang saling berkaitan. Dengan kata lain model juga dapat dipandang sebagai upaya mengkongkretkan sebuah teori sekaligus juga merupakan sebuah analogi daan reprentasi dari variable-variabel yang terdapat di dalam teori tersebut (Pribadi 2010).

Menurut Putra (2011) mengemukakan: 
R\&D didefinisikan sebagai metode penelitian yang secara sengaja, sitematis, bertujuan/diarahkan untuk mencari temukan, merumuskan, memperbaiki, mengembangkan, menghasilkan, menguji, keefektifannya produk, model, metode/strategi/cara, jasa, prosedur tertentu yang lebih unggul, baru, efektif, efisien, produktif dan bermakna.

Metode penelitian pada dasarnya merupakan cara ilmiah untuk mendapatkan data untuk mencapai tujuan tertentu dan memperoleh kegunaan tertentu. Dalam dunia pendidikan, penelitian memiliki tujuan untuk memecahkan masalah yang terjadi dengan menjawab secara ilmiah (Sugiyono 2013; Sukmadinata 2012). Setyosari (2013) menyebutkan bahwa penelitian merupakan suatu cara yang tepat dan sangat berguna dalam memperoleh informasi yang sahih dan dapat dipertanggungjawabkan.

Dalam pencak silat terdapat teknik dasar pencak silat yaitu, (1) belaan, (2) serangan, (3) menjatuhkan, (4) jurus, (5) pasang. Johansyah Lubis mengatakan gerak dasar pencak silat merupakan gerak terencana, terarah, terkordinasi dan terkendali yang memiliki aspek sebagai satu kesatuan, yaitu aspek mental, spiritual, beladiri, olah raga dan seni budaya (Lubis 2014b; Hariyadi 2009). Tendangan lurus adalah serangan yang menggunakan sebelah kaki dan tungkai, lintasannya ke arah depan dengan posisi badan menghadap depan, dengan kenaannya pangkal jari-jari kaki bagian dalam, dengan sasaran uluh hati dan dagu (Lubis 2014b, 2014a).

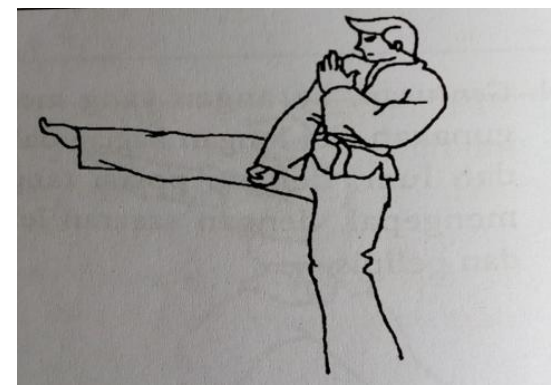

Gambar 1. Tendangn lurus 


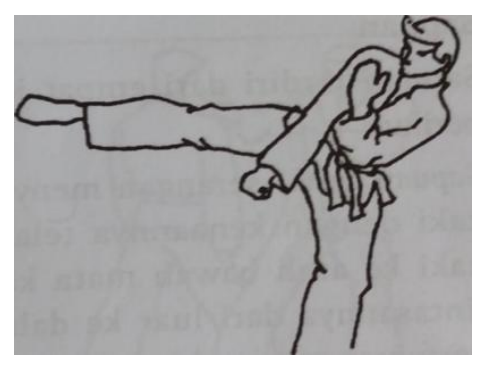

Gambar 2. Tendangan sabit

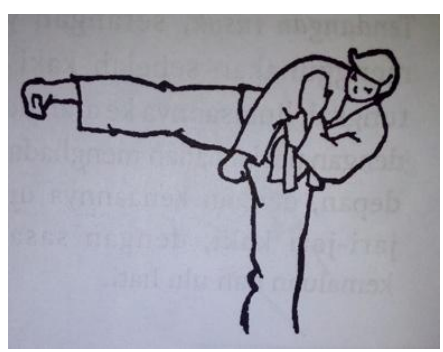

Gambar 3. Tendangan T

Tendangan sabit, merujuk pada namanya, merupakan suatu teknik tendangan yang lintasan geraknya membentuk garis setengah lingkaran atau tendangan ini cara kerjanya mirip dengan sabit, yaitu diayun dari samping luar menuju samping dalam. Serangan yang menggunakan sebelah kaki dan tungkai, lintasannya lurus ke depan dan keaannya pada tumit, telapak kaki, dan sisi luar telapak kaki, posisi lurus, biasanya digunakan untuk serangan samping, dengan sasaran seluruh bagian tubuh (Lubis 2014b).

Tendangan belakang, Melaksanakan ini, pesilat dari sikap pasang harus melakukan putaran tubuh(berbalik) terlebih dahulu, sehingga ia berada dalam posisi membelakangi lawan. Pastikan pantat dan punggung benar-benar telah berada pada posisi lurus dengan lawan (sasaran). Kemudian, dengan sedikit menekuk lutut (kaki yang menendang) dan tanpa memutar pinggul, dorongkan tungkai ke arah lawan. Daerah perkenaan teknik tendangan ini adalah tumit. 


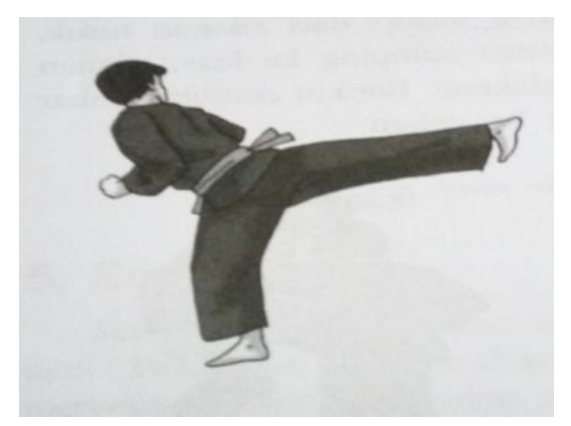

Gambar 4. Tendangan Belakang

\section{METODE}

Penelitian ini dilaksanakan di SMA 1 Maniangpajo, SMK Darussalam Makassar dan SMA 3 Sungguminasa. Waktu penelitian ini direncanakan selama 2 (dua) bulan. Pengguna yang menjadi sasaran dalam penelitian pengembangan model pembelajaran teknik tendangan pencak silat untuk SMA ini adalah dengan karakteristik sebagai berikut: 1) Siswa duduk di jenjang SMA. 2) Siswa berusia sekitar 17-18 tahun (subjek homogen), ini diasumsikan agar dapat mempermudah pelaksanaan uji coba produk. Teknik pengambilan subyek yang diterapkan dalam penelitian ini merupakan sampling purposif, yang dikenal juga sebagai sampling pertimbangan atau berdasarkan pertimbangan tertentu. Berikut ini merupakan kriteria subjek penelitian, yang akan dijelaskan pada Tabel 1 berikut ini:

Tabel 1. Subjek Penelitian

\begin{tabular}{|c|c|c|c|c|}
\hline No & $\begin{array}{c}\text { Tahap } \\
\text { Penelitian }\end{array}$ & $\begin{array}{l}\text { Jumlah } \\
\text { Subyek }\end{array}$ & Kriteria & Instrumen \\
\hline 1 & $\begin{array}{l}\text { Penelitian } \\
\text { Pendahuluan }\end{array}$ & 1 & $\begin{array}{l}\text { - } 1 \text { Orang guru } \\
\text { Penjasorkes }\end{array}$ & - Wawancara \\
\hline 2 & Evaluasi Pakar & 3 & $\begin{array}{l}\text { - } 2 \text { Orang Ahli } \\
\text { pencaksilat } \\
\text { - } 1 \text { Orang Ahli } \\
\text { Penjaskes }\end{array}$ & $\begin{array}{ll}\text { - } & \text { Lembar } \\
\text { Kuesioner }\end{array}$ \\
\hline 3 & $\begin{array}{l}\text { Evaluasi } \\
\text { Instrumen }\end{array}$ & 3 & $\begin{array}{l}\text { - } 1 \text { Orang dosen ahli tes } \\
\text { dan pengukuran } \\
\text { - } 3 \text { Orang dosen ahli } \\
\text { pencak silat. }\end{array}$ & $\begin{array}{ll}\text { - } & \text { Lembar } \\
\text { Kuesioner }\end{array}$ \\
\hline 4 & $\begin{array}{l}\text { Uji Coba Produk } \\
\text { a. } \begin{array}{l}\text { Preliminary } \\
\text { Field Testing }\end{array}\end{array}$ & 30 & - 30 Orang siswa SMA & 35 model \\
\hline & b. Main Field & 90 & - 90 Orang siswa SMA & 35 model yang \\
\hline
\end{tabular}




\begin{tabular}{llcll}
\hline No & $\begin{array}{l}\text { Tahap } \\
\text { Penelitian }\end{array}$ & $\begin{array}{c}\text { Jumlah } \\
\text { Subyek }\end{array}$ & \multicolumn{1}{c}{ Kriteria } & \multicolumn{1}{c}{ Instrumen } \\
\hline & Testing & & $\bullet 40$ Orang siswa SMA & telah direvisi \\
& & & & 35 model yang \\
c. & $\begin{array}{l}\text { Operational } \\
\text { Field }\end{array}$ & 40 & & $\begin{array}{l}\text { telah direvisi dari } \\
\text { Testing/kelay }\end{array}$ \\
akan & & & Main Fiedl \\
& & & Testing \\
\hline
\end{tabular}

Penelitian pengembangan model pembelajaran pencak silat berupa tendangan lurus/depan dan tendangan sabit menggunakan model penelitian dan pengembangan (Reseach and Development) dari Borg and Gall (2009:775) yang terdiri dari sepuluh langkah yakni antara lain:(1)Reseach and information collecting (2) Planning (3) Development of the preliminary from of product (4) Preliminary field testing (5) Main product revision (6) Main field test. (7) Operational product revision (8) Operational field testing. (9) Final produk (10) Dissemination and implementation (Gall and Meredith 1983).

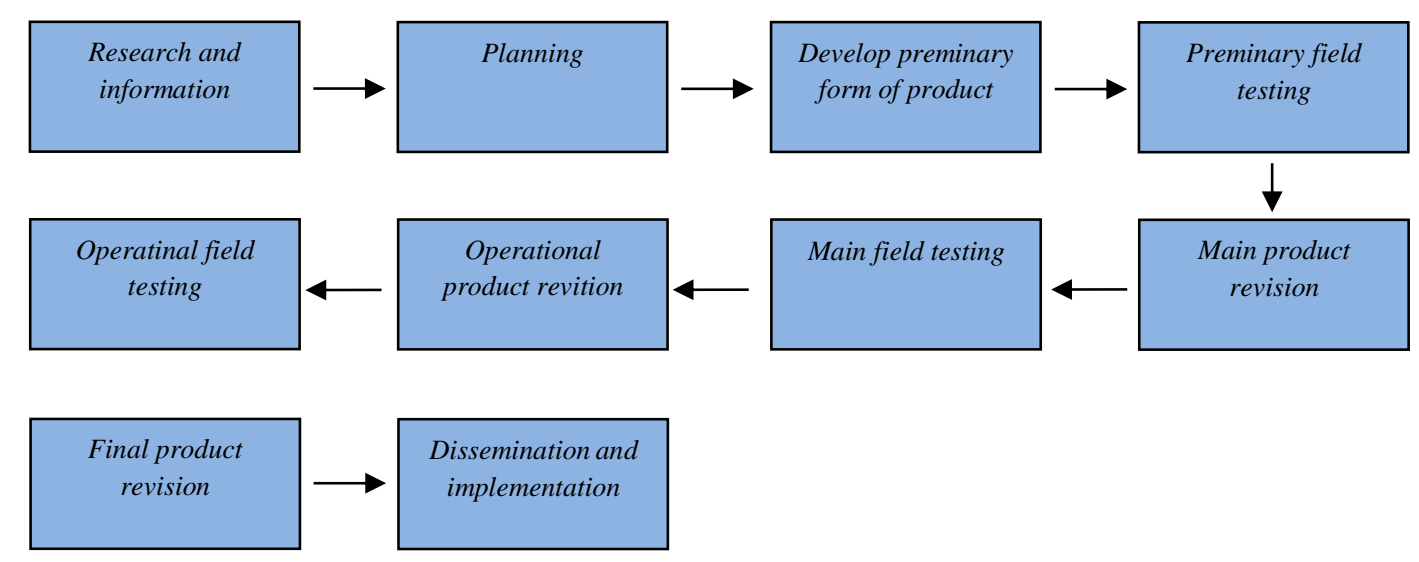

Gambar 1. Alur Pengembangan

Pada penelitian dan pengembangan ini tentunya diharapkan akan menghasilkan sebuah produk yang dapat digunakan pada mata pelajaran pendidikan jasmani khususnya pembelajaran pencak silat untuk anak sekolah menengah atas (SMA) dengan desain model baru atau menyempurnakan yang telah ada secara lengkap sehingga bisa dijadikan sumber belajar lain dalam proses belajar mengajar 


\section{HASIL DAN PEMBAHASAN}

Setelah melalui uji coba kelompok kecil dan revisi tahap kedua komponen produk pengembangan model pembelajaran keterampilan tendangan pencak silat, dilanjutkan dengan uji coba lapangan dan revisi tahap ketiga komponen produk pengembangan model pembelajaran keterampilan tendangan pencak silat, maka untuk mengetahui rata-rata efektifitas produk, dilakukan proses implementasi dengan pengumpuln data uji efektifitas menggunakan uji $\mathrm{T}$ dengan software SPSS.Ujii coba produk dilaksanakan oleh 40 siswa.

Tabel 2. Hasil Rata-rata Pretest dan Post Test Uji efektivitas Model Pembelajaran Keterampilan Pencak Silat

\begin{tabular}{|c|c|c|c|}
\hline \multirow{2}{*}{ No } & \multirow{2}{*}{ Nama } & \multicolumn{2}{|c|}{ Tendangan Pencak Silat } \\
\hline & & Pre Test & Post Test \\
\hline 1 & Aris Munandar & 41.25 & 86.25 \\
\hline 2 & Agung Wijaya & 44.37 & 85.93 \\
\hline 3 & Ahmad & 44.37 & 85.62 \\
\hline 4 & Sihab & 45.94 & 84.37 \\
\hline 5 & Andi Anas & 42.81 & 89.68 \\
\hline 6 & Hendri & 42.18 & 85.62 \\
\hline 7 & Roqib & 42.05 & 88.43 \\
\hline 8 & Irfan & 43.12 & 84.68 \\
\hline 9 & M.Yunus & 41.25 & 85.93 \\
\hline 10 & Agustan & 43.43 & 85.00 \\
\hline 11 & Subhan & 42.05 & 85.00 \\
\hline 12 & Syahrul & 40.62 & 87.81 \\
\hline 13 & Dirhanuddin & 42.81 & 88.12 \\
\hline 14 & Hasan & 41.25 & 87.18 \\
\hline 15 & Taufiq & 39.68 & 85.93 \\
\hline 16 & Yogi & 40.62 & 85.93 \\
\hline 17 & Muhammad Aspar & 41.87 & 86.56 \\
\hline 18 & Rahmat & 41.87 & 88.43 \\
\hline 19 & Reza & 38.12 & 85.31 \\
\hline 20 & Juhasdi & 38.43 & 86.25 \\
\hline 21 & Dedy Riadi & 41.87 & 85.62 \\
\hline 22 & Arifuddin & 40.00 & 84.06 \\
\hline 23 & Hamka & 40.31 & 85.31 \\
\hline
\end{tabular}




\begin{tabular}{llcc}
\hline \multirow{2}{*}{ No } & & \multicolumn{2}{c}{ Nendangan Pencak Silat } \\
\cline { 3 - 4 } & & Pre Test & Post Test \\
\hline 24 & Aswandi & 41.56 & 85.62 \\
\hline 25 & Agus Salim & 40.00 & 86.56 \\
\hline 26 & Ridwan Bae & 40.62 & 86.87 \\
\hline 27 & Suhardi & 39.68 & 84.06 \\
\hline 28 & Baso Askar & 42.05 & 85.62 \\
\hline 29 & Andi Gusti & 41.25 & 84.68 \\
\hline 30 & Rudi Widodo & 47.18 & 86.25 \\
\hline 31 & Adrian & 42.05 & 84.06 \\
\hline 32 & Jusriadi & 45.00 & 84.68 \\
\hline 33 & Dahlan & 45.31 & 85.00 \\
\hline 34 & Muliadi & 43.43 & 86.87 \\
\hline 35 & Asman Ala & 42.81 & 86.25 \\
\hline 36 & Baso Oddang & 43.75 & 83.75 \\
\hline 37 & Arisal & 41.56 & 85.93 \\
\hline 38 & Hasim & 43.43 & 82.05 \\
\hline 39 & Vikis & 44.68 & 84.37 \\
\hline 40 & Asnawi & 42.81 & 85.93 \\
\hline & Jumlah Rata-Rata & 42.23 & 85.80 \\
\hline
\end{tabular}

Di atas telah dipaparkan tabel hasil rata-rata uji pre test dan post test tendangan pencak silat. Uji pre test dilakukan setelah uji kelompok besar. Pre test dilakukan sebelum menerapkan 35 model pembelajaran tendangan pencak silat. Hasil rata-rata pre test pembelajaran keterampilan tendangan pencak silat yaitu 42.23 setelah dilakukan perlakuan dengan 35 model pembelajaran keterampilan tendangan selanjutnya setelah perlakuan maka dilakukan post test atau test akhir dan nilai rata-rata post testnya adalah 85.80. Berdasarkan uraian diatas, maka nilai rata-rata hasil pembelajaran keterampilan pencak silat antara pretest dan posttest akan diuraikan dalam Uji T Paired Sample Test dengan SPSS 16 dibawah ini:

Table 3. Tendangan Pencak Silat

Paired Samples Statistics

\begin{tabular}{lccccc}
\hline & Mean & N & $\begin{array}{c}\text { Std. } \\
\text { Deviation }\end{array}$ & Std. Error Mean \\
\hline Pair 1 & pretest & 42.23 & 40 & 1.96 & .310 \\
\hline
\end{tabular}




\section{Paired Samples Statistics}

\begin{tabular}{lccccc}
\hline & Mean & N & $\begin{array}{c}\text { Std. } \\
\text { Deviation }\end{array}$ & Std. Error Mean \\
\hline Pair 1 & pretest & 42.23 & 40 & 1.96 & .310 \\
\cline { 2 - 6 } & posttest & 85.80 & 40 & 1.42 & .225 \\
\hline
\end{tabular}

Berdasarkan hasil output dengan menggunakan SPSS 16 bahwa nilai ratarata hasil keterampilan tendangan pencak silat sebelum diberikan model 42.23 dan setelah diberikan perlakuan dengan model 85.80 artinya bahwa nilai rata-rata pembelajaran keterampilan tendangan pencak silat ada peningkatan.

Table 4. Tendangan Pencak Silat Paired Samples Test

\begin{tabular}{|c|c|c|c|c|c|c|c|c|}
\hline & \multicolumn{5}{|c|}{ Paired Differences } & \multirow{3}{*}{$\mathbf{t}$} & \multirow{3}{*}{ df } & \multirow{3}{*}{$\begin{array}{l}\text { Sig. (2- } \\
\text { tailed) }\end{array}$} \\
\hline & \multirow[t]{2}{*}{ Mean } & \multirow{2}{*}{$\begin{array}{c}\text { Std. } \\
\text { Deviati } \\
\text { on }\end{array}$} & \multirow{2}{*}{$\begin{array}{l}\text { Std. } \\
\text { Error } \\
\text { Mean }\end{array}$} & \multicolumn{2}{|c|}{$\begin{array}{c}95 \% \text { Confidence } \\
\text { Interval of the } \\
\text { Difference }\end{array}$} & & & \\
\hline & & & & Lower & Upper & & & \\
\hline $\begin{array}{cc}\text { Pair } & \text { pretest - } \\
1 & \text { posttest }\end{array}$ & 43.57 & 2.58750 & .40912 & 44.39783 & 42.74279 & 106.498 & 39 & .000 \\
\hline
\end{tabular}

Dalam uji signifikansi perbedaan dengan SPSS 16 dapat hasil t-hitung= 43.57, df $=39$ dan $\mathrm{p}$-value $=0.00<0.05$ yang berarti terdapat perbedaan yang signifikan pembelajaran keterampilan tendangan pencak silat sebelum dan sesudah adanya perlakuan model tendangan pencak silat. Berikut diagram perbandingan hasil rata-rata dari tingkat tes tendangan pencak silat sebelum pemberian treatmen dan sesudah pemberian perlakuan dengan model-model tendangan pencak silat dengan diagram batang pada gambar berikut ini: 


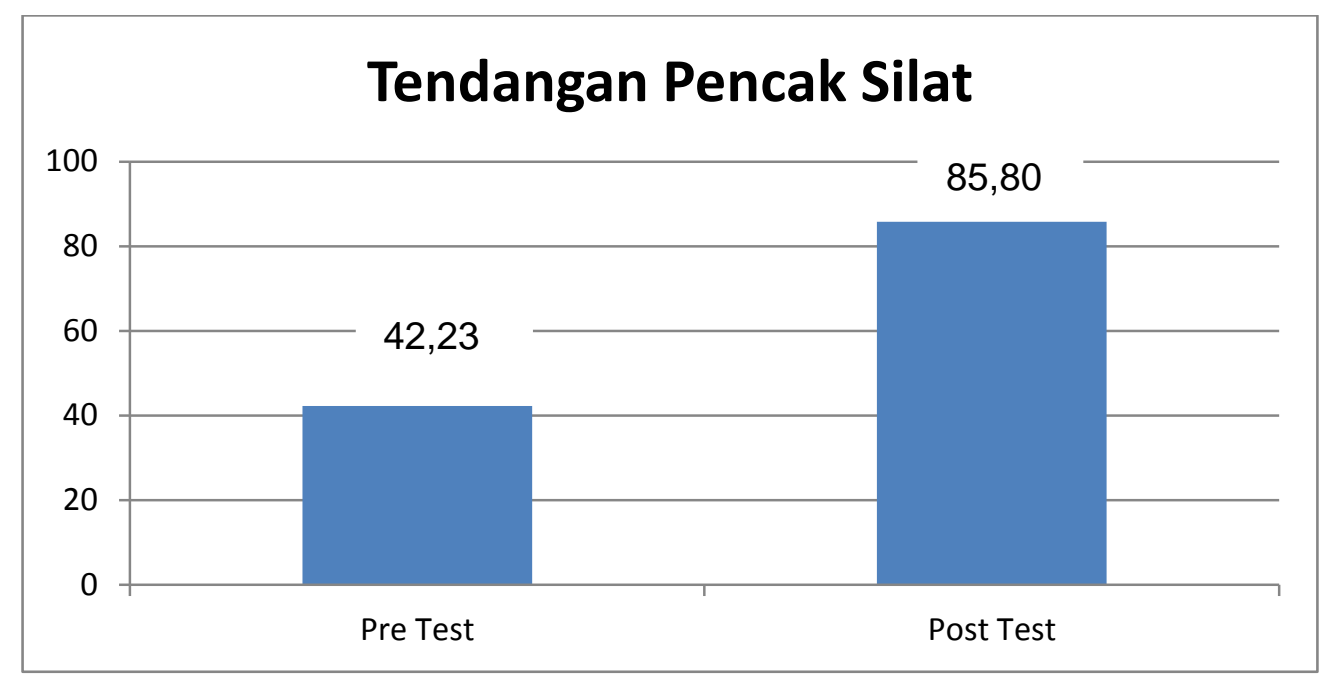

Gambar 2. Diagram Batang keterampilan Pencak Silat Tendangan (Uji Efektivitas Model)

Dari hasil penelitian yang telah dilakukan dapat disimpulkan bahwa dengan model pembelajaran keterapilan tendangan pencak silat untuk siswa SMA dapat dikembangkan dan diterapkan dalam pembelajaran pendidikan jasmani di sekolah. Selain itu dengan model pembelajaran keterampilan tendangan pencak silat untuk siswa SMA yang telah dikembangkan, diperoleh bukti adanya peningkatan ini di tunjukan pada hasil pengujian data hasil pretes dan posttest adanya perbedaan yang signifikan antara sebelum dan sesudah adanya perlakuan model.

\section{DAFTAR RUJUKAN}

Gall, Borg Walter R, and Meredith. 1983. Fouth Edition Research An Introduction. USA: Logman.

Genel, Wilkinson. 1980. Media Dalam Pembelajaran: Penelitian Selama 60 Tahun. Jakarta: Pustekkom Dikbud dan CV. Rajawali.

Hariyadi, Kotot Slamet. 2009. Teknik Dasar Pencak Silat. Jakarta: Dian Rakyat.

Hariyanto, Suryono. 2013. Belajar Dan Pembelajaran. Bandung: PT. Remaja Rosdakarya.

Kemenagpora. 2011. Undang-Undang Republik Indonesia Nomor 3 Tahun 2005: Tentang Sistem Keolahragaan Nasional. Indonesia: Kemenagpora.

Lesmana, Ferry. 2012. Panduan Pencak Silat. Yogyakarta: Zanafa Publishing. Lubis. 2014a. Pencak Silat Panduan Praktis. Jakarta: PT. Raja Grafindo Persada. 
Lubis, Johansyah. 2014b. Pencak Silat. Jakarta: PT. Raja Grafindo Persada.

Musfiqon. 2012. Pengembangan Media Dan Sumber Belajar. Jakarta: Prestasi Pustaka.

Naharsari, Nur Dyah. 2008. Olahraga Pencak Silat. Jakarta: Ganaxa Exat.

Nara, Evelin Siregar, and Hartini. 2010. Belajar Dan Pembelajaran. Bogor: Ghalia Indonesia.

Pribadi, Benny A. 2010. Pribadi.Pdf. Jakarta: Dian Rakyat.

Putra, Nusa. 2011. Putra.Pdf. Jakarta: PT. Raja Grafindo Persada.

Setyosari, Punaji. 2013. Setyosari, Punaji. Jakarta: Prenada Media Group.

Sihkabuden, Punaji Setyosari. 2005. Media Pembelajaran. Malang: Elang Mas.

Sugiyono. 2013. Sugiyono.Pdf. Bandung: Alfabeta.

Sukmadinata, Nana Syaodih. 2012. Sukmadinata.Pdf. Bandung: Rosdakarya.

Tangkudung, James. 2013. Kepelatihan Olahraga. Jakarta: Cerdas Jaya.

Tite, Juliantine. 2013. Model-Model Pembelajaran Dalam Pendidikan Jasmani. Bandung: Bintang Warli Artika.

Winarno. 2011. Metodologi Penelitian Dalam Pendidikan Jasmani. Malang: Media Cakrawala Utama Press.

Zain, Syaiful Bahri D, and Aswan. 2006. Strategi Belajar Mengajar. Jakarta: PT. Asdi Mahasatya. 